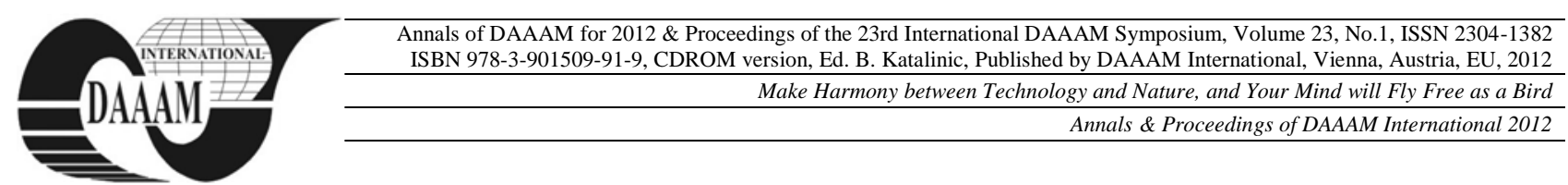

\title{
ON NONLINEARITIES OF VIADUCTS BEARINGS AS PRIMARY FACTOR OF DYNAMIC RESPONSE
}

\author{
LEOPA, A[drian]; DEBELEAC, C[armen] N[icoleta]; NASTAC, S[ilviu] \& MLADIN, G[heorghe]
}

\begin{abstract}
In view of viaducts designing and safety exploitation it is necessary to evaluation both theoretical, and instrumental the dynamic behaviour for impulsive external actions. In this study the dynamic response for a singular bridge section was analyzed. It was considered only two degrees of freedom and the impulsive perturbations derived from the serviceable instrumental tests performed for this kind of construction objective at its managing to action.

Keywords: viaduct, dynamic, vibration, nonlinear
\end{abstract}

\section{INTRODUCTION}

A bridge or viaduct managing to action it was obligatory performed a succession of instrumental tests from static and dynamic point of view. The dynamic tests have a purpose to evaluate the dynamic response parameters framing for a certain bridge or viaduct structure into the regulated range of values for this kind of constructions. Periodic evaluation of these parameters and their comparative analysis constitute an efficient method for damages identification which can appears both on the structure, and on the bearings. With the other words the structural damages and the bearings failures will be identified through a nonlinear behaviour emergence for some essential dynamic response parameters [1]. For this analysis was proposed a complex physical and mathematical model based on it was demonstrates that the wearing out emergence into the bridge section bearings and implicit the nonlinear behaviour of the resistant forces generated by these leads to qualitative and quantitative modifications of the dynamic response parameters of the base structure. At international level a great attention is offered to identification and to quantification of a bridge failure, but with hydraulics dampers mounted on sections supports. This is a modern and efficient technique for bridge damaging management and such algorithm was successfully applied for structural integrity qualification of Vincent Thomas Bridge in Los Angeles [2].

\section{BRIDGE CHARACTERIZATION}

Avoiding destructive effects about the viaducts due to the dynamic actions derived from earthquakes or road traffic can be done by different types of passive systems for dynamic insulation. Such category is described by visco-elastic passive systems like the laminated rubber bearings.

This kind of dynamic isolation systems was used such as insulation devices for sections on bridge piles, for the viaduct of Transylvania A3 highway in Romania placed at 29+602.75 $\leftrightarrow 29+801.25$ km (at Săvădisla, between Târgu Mureş and Cluj Napoca cities) [3]. Due to seismic actions, road traffic and environmental factors the rubber base materials have changed their properties in time which also lead to modifications of bridge dynamic response on impulsive external excitations. Hereby it is necessary the insulation systems replacing to avois the partial or total demotion of the base structure of the bridge.

This study presents an evaluation methodology for the ordinary working state of a viaduct bearing systems based on the next suppositions as follows

- achievement of the predictive maintenance of antiseismic systems which enable their changing at a right moment;

- post-seismic diagnosis of anti-seismic systems based on their dynamic response at impulsive actions [4].

The viaduct infrastructure consists of two sections and four piles for each direction of traffic (see Fig.1). The viaduct superstructure is transversely composed by four "U" type beams preformed and disposed between $3.32 \mathrm{~m}$ each other (between their longitudinal axes). Over these beams it was found a concrete super-slab of $25 \mathrm{~cm}$ thickness. The beams material was pre-casting reinforced concrete of $\mathrm{C} 35 / 45$ class, and the super-slab material was $\mathrm{C} 25 / 30$ class reinforced concrete. The viaduct has five sections of $40 \mathrm{~m}$ length. The global insulation of the superstructure onto infrastructure, sections and piles elements was assured with Freyssinet $(\mathrm{C}$ type rubber bearings of $81 \mathrm{~mm}$ height.

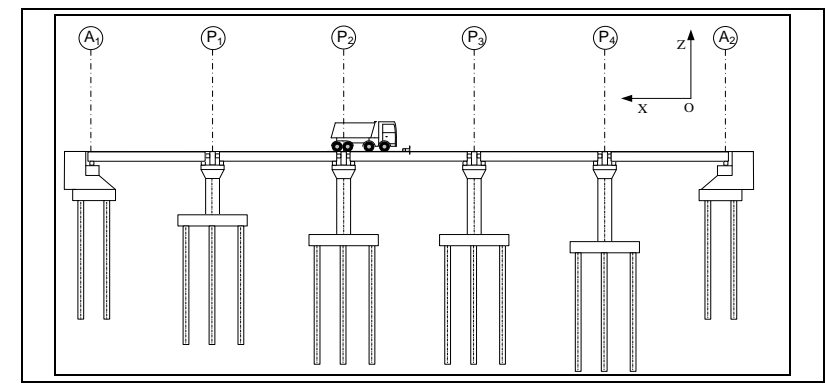

Fig. 1. The viaduct longitudinal profile

The study presented in this paper has evaluated and quantified the dynamic response of the viaduct section between P2 and P3 piles for a truck tip passing over a regulated bump according SR12504/86 - Superstructures testing with trial actions (see Fig.2). This configuration was based on the hypothesis according to the proposed 
section have independent movement of the other because of its free ends.

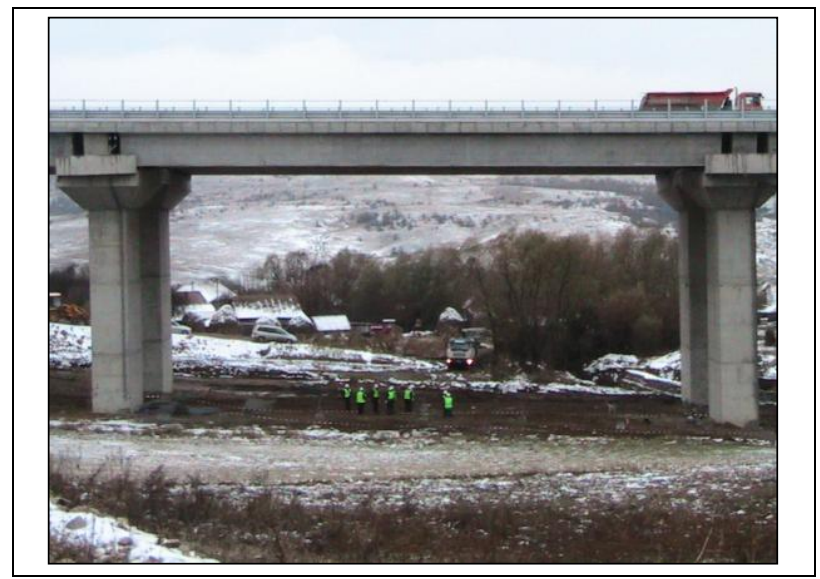

Fig. 2. Viaduct on the A3 Transylvania Highway

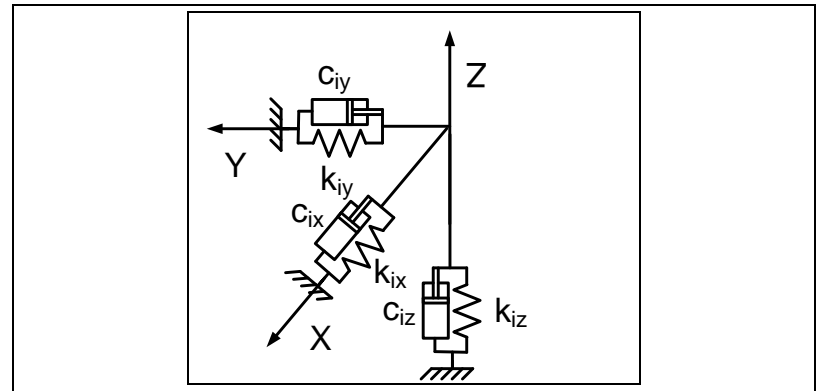

Fig. 3. Spatial orthogonal visco-elastic bearing

The infrastructure of the analyzed section is insulated on 16 visco-elastic elements with spatial orthogonal distribution such as the model in Fig.3.

\section{THEORETICAL PHYSICAL AND MATHEMATICAL MODEL}

For the physical and mathematical computational modeling of mechanical system subjected to external dynamic actions it is very important an appropriate defining of the excitation impulsive functions in respect with the shape, magnitude and time length of their effective application.

\subsection{The excitation force of the section}

According to SR12504/86 the bridge section was tested with impulsive force generated by a truck tip with four axles and 41 tones total mass passing with $20 \mathrm{~km} / \mathrm{h}$ over a bump with $40 \mathrm{~mm}$ regulated height (see Fig.4).

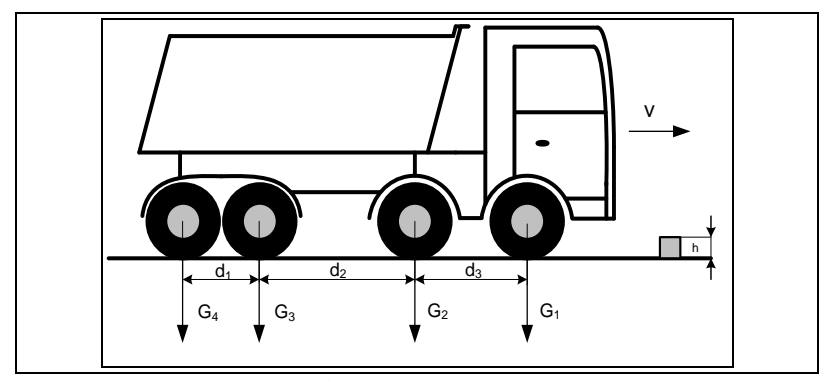

Fig. 4. The truck tip model for dynamic instrumental testing where $\mathrm{m}_{1}=7440 \mathrm{~kg}, \mathrm{~m}_{2}=7339 \mathrm{~kg}, \mathrm{~m}_{3}=13149 \mathrm{~kg}$, $\mathrm{m}_{4}=13149 \mathrm{~kg}, \mathrm{~d}_{1}=1.5 \mathrm{~m}, \mathrm{~d}_{2}=2.5 \mathrm{~m}, \mathrm{~d}_{3}=2.0 \mathrm{~m}, \mathrm{~h}=40$ $\mathrm{mm}$.

The percussion forces was evaluated with the mathematic expression as follows [5]

$$
F_{y}=\frac{m_{0}}{3 \Delta t} \frac{h}{R}\left(2 \frac{h}{R}-5\right)
$$

where $\mathrm{h}=0.04 \mathrm{~m}$ is the bump height, $\mathrm{R}=1.2 \mathrm{~m}$ denotes the wheel diameter, $\Delta \mathrm{t}=0.03 \mathrm{~s}$ is the duration of the bump over passing; $m$ denotes the mass distributed on the axle; $\mathrm{v}_{0}=20 \mathrm{~km} / \mathrm{h}$ is the truck tip velocity at the bump over passing. The excitation forces due to the bump over passing for each axle have the next values: $\mathrm{F}_{\mathrm{y} 1}=1.4751 \cdot 10^{5} \mathrm{~N} ; \mathrm{F}_{\mathrm{y} 2}=1.4551 \cdot 10^{5} \mathrm{~N} ; \mathrm{F}_{\mathrm{y} 3}=2.6071 \cdot 10^{5} \mathrm{~N}$; $\mathrm{F}_{\mathrm{y} 4}=2.6071 \cdot 10^{5} \mathrm{~N}$.

Supposing that the excitation function have an approximate rectangular shape the global external action on the bridge section is composed by a succession of four rectangular pulses such as in diagram depicted in Fig. 5.

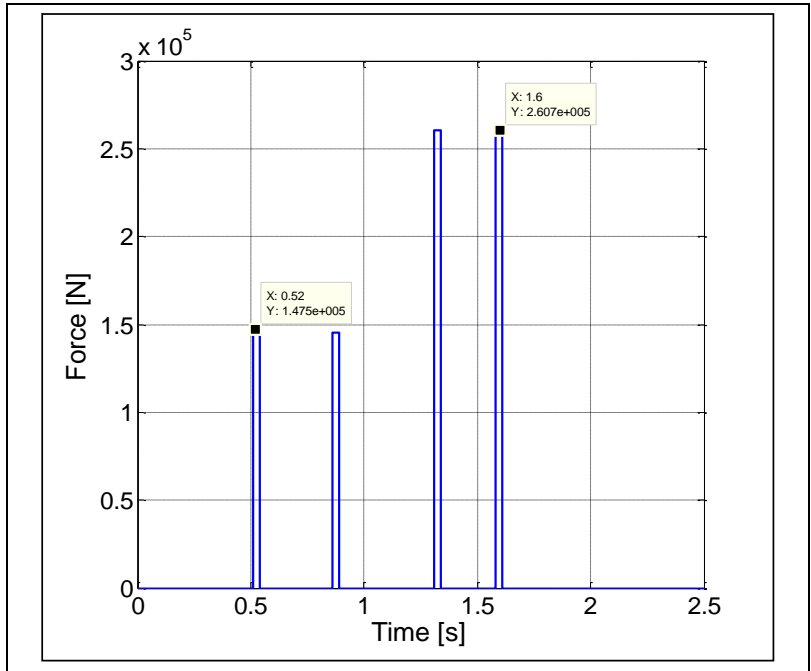

Fig. 5 .Four rectangular pulses excitation signal

\subsection{Mathematical characterization of dynamic system}

In view of physical model assembling it was treated the bridge section such as a rigid body insulated on 16 visco-elastic spatial orthogonal elements - see model in Fig. 6.

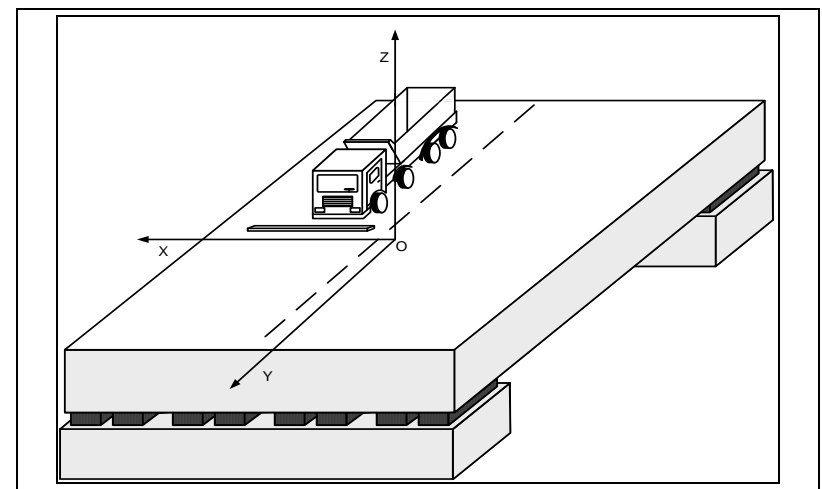

Fig. 6. The schematic diagram of the viaduct section model with external excitation system and neoprene bearings 
The general expression of the oscillating movement system equation can be written as follows [6]

$$
\underline{\underline{I}} \underline{\underline{q}}+\underline{C} \underline{\underline{\dot{q}}}+\underline{\boldsymbol{K}} \underline{\underline{q}}=\underline{=}
$$

where

$q$ denotes the generalized coordinates vector;

$\dot{q}$ is the generalized velocities vector;

$\ddot{q}$ denotes the generalized accelerations vector;

$\underline{f}$ denotes the generalized forces vector;

$\underline{I}$ is the matrix of inertial terms;

$\underline{C}$ denotes damping terms matrix;

$\underline{K}$ is the rigidity matrix.

The principal elastic axis of the elastic bearings is in parallel with the reference axis. In this case the movements due to coordinates variations according to the six degrees of freedom becomes uncoupled as follows

- the coupled translation along the $X$ axis and the rotational around the $\mathrm{Y}$ axis movements $\left(\mathrm{X}, \varphi_{\mathrm{y}}\right)$;

- the coupled translation along the $\mathrm{Y}$ axis and the rotational around the $\mathrm{X}$ axis movements $\left(\mathrm{Y}, \varphi_{\mathrm{x}}\right)$;

- the translation movement along the $\mathrm{Z}$ axis independent of the other modes;

- the rotational movement around the $\mathrm{Z}\left(\varphi_{\mathrm{z}}\right)$ axis independent of the other modes.

In this case the differential equations system can be structured as follows [7]

- Coupled mode $\left(X, \varphi_{y}\right)$

$$
\left\{\begin{array}{l}
m \ddot{X}+\dot{X} \sum_{l}^{16} c_{i x}+\dot{\phi}_{y} \sum_{l}^{16} z_{i} c_{i x}+X \sum_{l}^{16} k_{i x}+ \\
+\phi_{y} \sum_{l}^{16} z_{i} k_{i x}=0 \\
J_{y} \ddot{\phi}_{y}+\dot{X} \sum_{l}^{16} z_{i} c_{i x}+\dot{\phi}_{y} \sum_{l}^{16}\left(c_{i z} x_{i}^{2}+c_{i x} z_{i}^{2}\right)+ \\
+X \sum_{l}^{16} z_{i} k_{i x}+\phi_{y} \sum_{l}^{16}\left(k_{z} x_{i}^{2}+k_{x} z_{i}^{2}\right)=e_{x} F_{z}
\end{array}\right.
$$

- Coupled mode $\left(\mathrm{Y}, \varphi_{\mathrm{x}}\right)$

$$
\left\{\begin{array}{l}
m \ddot{Y}+\dot{Y} \sum_{l}^{16} c_{i y}-\dot{\phi}_{x} \sum_{l}^{16} c_{i y} z_{i}+Y \sum_{l}^{16} k_{i y}- \\
-\phi_{x} \sum_{I}^{16} k_{i y} z_{i}=0 \\
J_{x} \ddot{\phi}_{x}-\dot{Y} \sum_{l}^{16} z_{i} c_{i y}+\dot{\phi}_{x} \sum_{l}^{16}\left(c_{i y} z_{i}^{2}+c_{i z} y_{i}^{2}\right)- \\
-Y \sum_{I}^{16} z_{i} k_{i y}+\phi_{x} \sum_{I}^{16}\left(k_{i y} z_{i}^{2}+k_{i z} y_{i}^{2}\right)=-e_{y} F_{y}
\end{array}\right.
$$

$$
m \ddot{Z}+\dot{Z} \sum_{I}^{16} c_{i z}+Z \sum_{l}^{16} k_{i z}=-F_{z}
$$

- Rotation around the $\mathrm{OZ}$ axis

$$
\begin{aligned}
& J_{z} \ddot{\phi}_{z}+\dot{\phi}_{z} \sum_{l}^{16}\left(c_{i x} y_{i}^{2}+2 c_{i y} x_{i}^{2}\right)+ \\
& +\phi_{z} \sum_{l}^{16}\left(k_{i x} y_{i}^{2}+2 k_{i y} x_{i}^{2}\right)=0
\end{aligned}
$$

where

$m$ is the deck bridge mass;

$c_{i z}$ denotes damping coefficient of bearing $\mathrm{i}$ on vertical direction;

$k_{i z}$ is the rigidity coefficient of bearing $\mathrm{i}$ on vertical direction;

$\mathrm{X}, \mathrm{Y}, \mathrm{Z}$ denote deck bridge displacements on $\mathrm{OX}, \mathrm{OY}$ and OZ directions;

$\phi_{x}, \phi_{y}$ denote the mass $m$ rotation movements around axes $\mathrm{OX}$ and $\mathrm{OY}$;

$x_{i}, y_{i}$ and $z_{i}$ represent the bearings coordinates;

$J_{x}, J_{y}, J_{z}$ - are the principal moments of inertia;

$e_{x}$ and $e_{y}$ denote the coordinates of the excitation force point of application measured for the mass center of the deck bridge; $F_{z}, F_{y}$ denote the excitation forces.

\section{ANALYSIS OF DECK BRIDGE DYNAMIC RESPONSE FOR COUPLED MODE OF FOLLOWING AND ROCKING MOVEMENTS}

Differential equations system (4) was numerical solved in MatlabR14C [8] software and it was analyzed the next parameters of the deck bridge vibratory movement as follows

- the displacement along OY direction in time and frequency domains;

- the acceleration along OY direction in time and frequency domains;

- acceleration spectrogram;

- movement stability through phases domain graphical analysis.

These parameters was comparative analyzed for two distinctive cases as follows [9]

- elastic forces along OY direction having linear evolution;

- elastic forces along OY direction having nonlinear evolution with the next displacement dependence expression

$$
\mathrm{F}_{\mathrm{y}}=\mathrm{Y}\left(1+\beta \mathrm{Y}^{2}\right) \sum_{1}^{16} \mathrm{k}_{\mathrm{iy}}
$$

where

- Translation along the $\mathrm{OZ}$ axis 
$\beta=5 \cdot 10^{8} \quad 1 / \mathrm{m}^{2} ; \quad k_{\mathrm{iy}}=3.15 \cdot 10^{6} \quad \mathrm{~N} / \mathrm{m} ; \quad c_{\mathrm{iy}}=2.5 \cdot 10^{5} \quad \mathrm{Ns} / \mathrm{m}$; $\mathrm{m}=992 \cdot 10^{3} \mathrm{~kg} ; \quad \mathrm{k}_{\mathrm{iz}}=650 \cdot 10^{6} \mathrm{~N} / \mathrm{m} ; \quad \mathrm{c}_{\mathrm{iz}}=2.5 \cdot 10^{6} \mathrm{Ns} / \mathrm{m}$; $\mathrm{m}=992 \cdot 10^{3} \mathrm{~kg} ; \mathrm{Jx}=120.533 \cdot 10^{6} \mathrm{kgm}^{2} ; \mathrm{e}_{\mathrm{y}}=2 \mathrm{~m}$.

\subsection{Deck bridge displacement along OY direction}

For the nonlinear case (see Fig.8) result a decreasing of displacement value to $2.9 \cdot 10^{-4} \mathrm{~m}$ comparative with $8.9 \cdot 10^{-4} \mathrm{~m}$ for the linear case (see Fig.7).

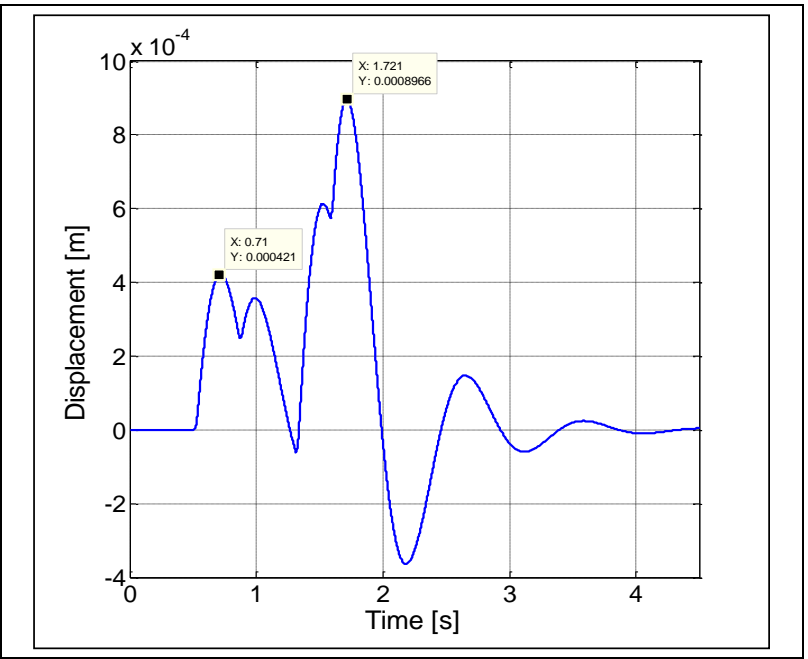

Fig. 7. Displacement of mass $m$ : linear case

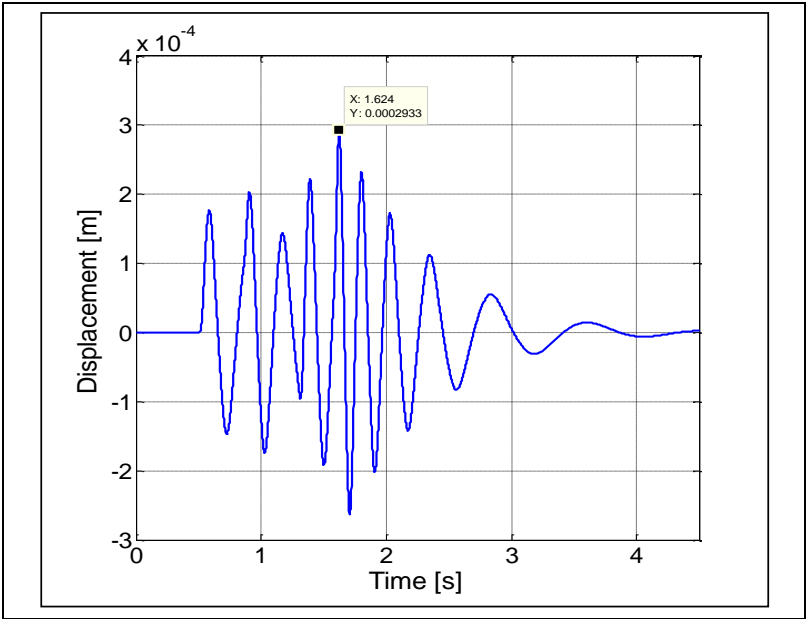

Fig. 8. Displacement of mass $m$ : nonlinear case

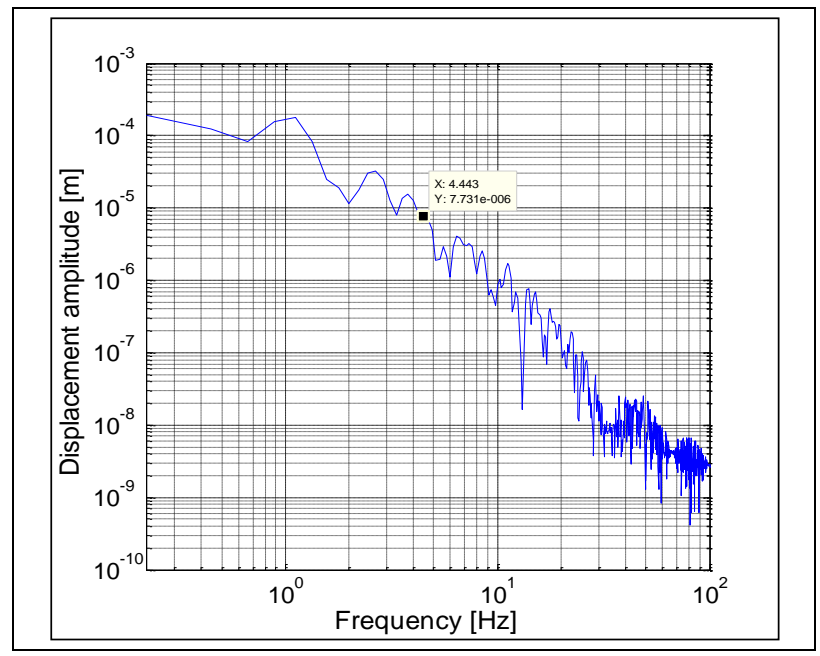

Fig. 9. Spectral composition of displacement in linear case
This reduction results from the bearings rubber reinforcement due to ageing phenomenon.

From the qualitative point of view it has to be pointed the distorted shape of displacement for the nonlinear case comparative with the linear.

From the frequency domain diagrams (see Fig. 9 and Fig. 10) of displacement parameter evolution results that nonlinearity imposes a shifting to the high frequencies of significant spectral components comparative with the linear case analysis. Hereby for the nonlinear case the significant spectral area is centered on $4.44 \mathrm{~Hz}$ value while that for the linear case this area is found around 0.5 $\mathrm{Hz}$ value.

\subsection{Deck bridge acceleration along OY direction}

Analyzing the acceleration diagrams depicted in Fig. 11 and Fig. 12 taking into account the qualitative point of view result a decreasing of acceleration magnitude to $0.04 \mathrm{~m} / \mathrm{s}^{2}$ in the nonlinear case comparative with $0.05 \mathrm{~m} / \mathrm{s}^{2}$ for the linear case. Also, the shape of the acceleration signal is very much distorted for nonlinear case relative to linear case.

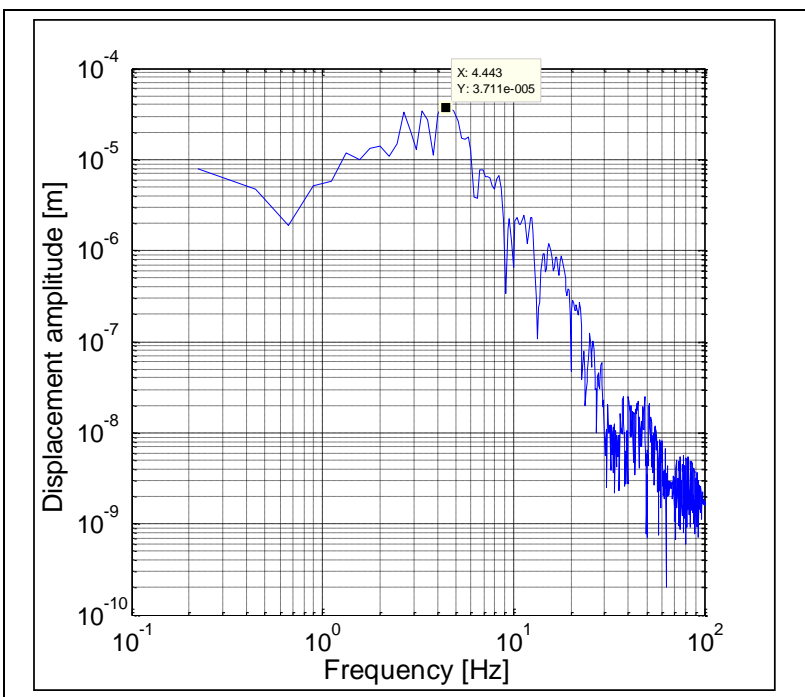

Fig. 10. Spectral composition of displacement in nonlinear case

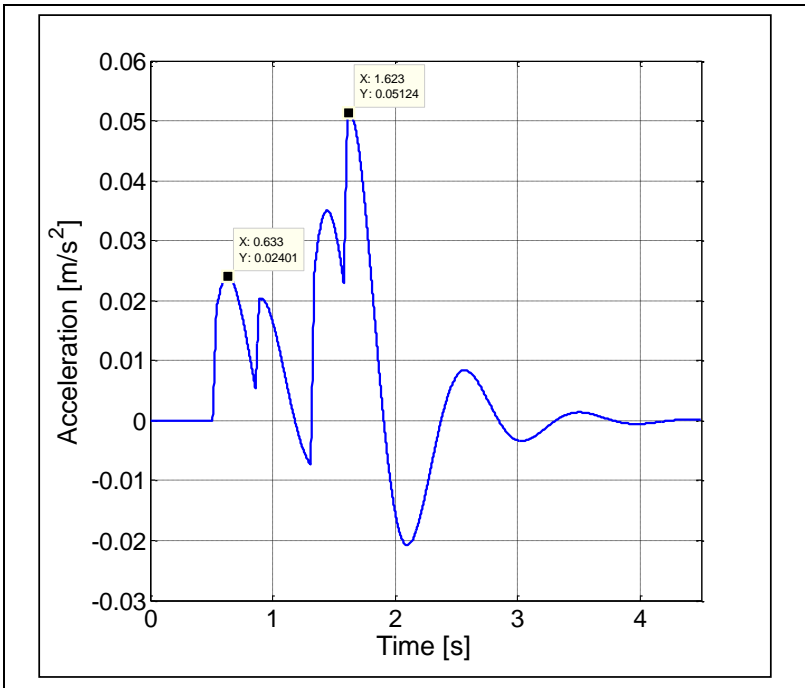

Fig. 11.Acceleration magnitude of mass $m$ - linear case 


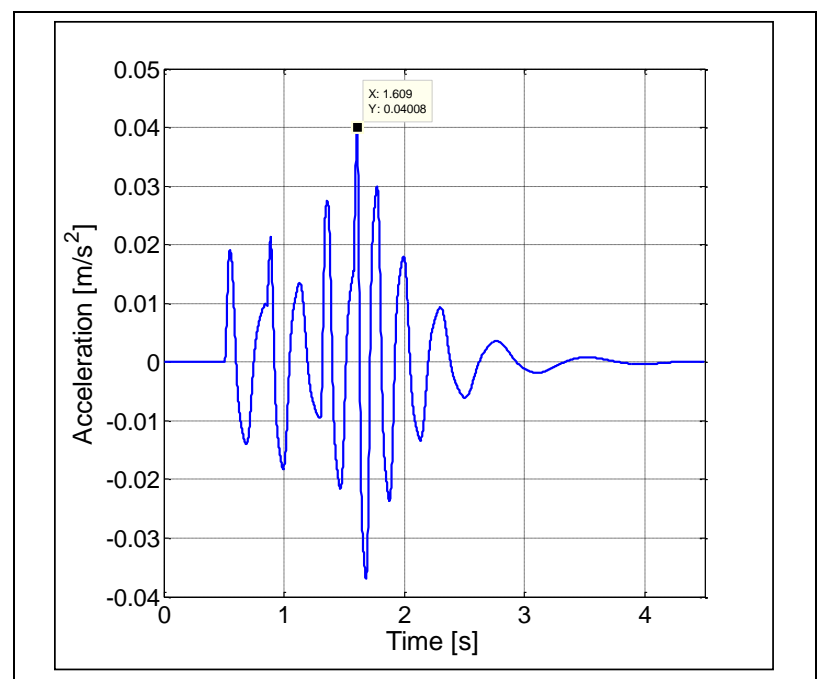

Fig. 12. Acceleration magnitude of mass $m$-nonlinear case

Spectral composition of acceleration signals depicted in diagrams in Fig. 13 and Fig. 14 also reveal a right side shifting to high frequencies of significant component area such as the displacements case. Hereby for the nonlinear case the central value or significant components area is $4.22 \mathrm{~Hz}$ while that for linear case this value is around $0.5 \mathrm{~Hz}$.

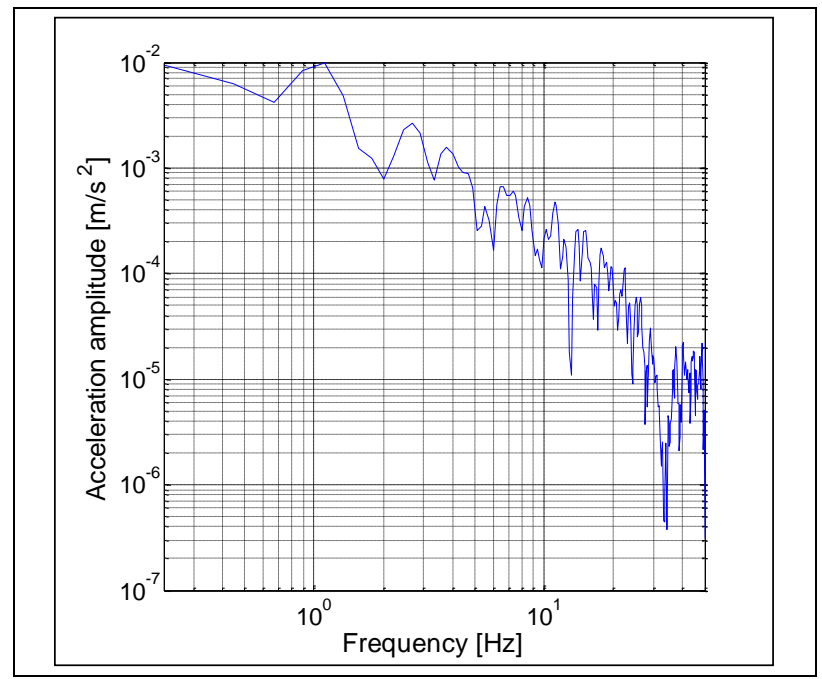

Fig. 13. Spectral composition of acceleration in linear case

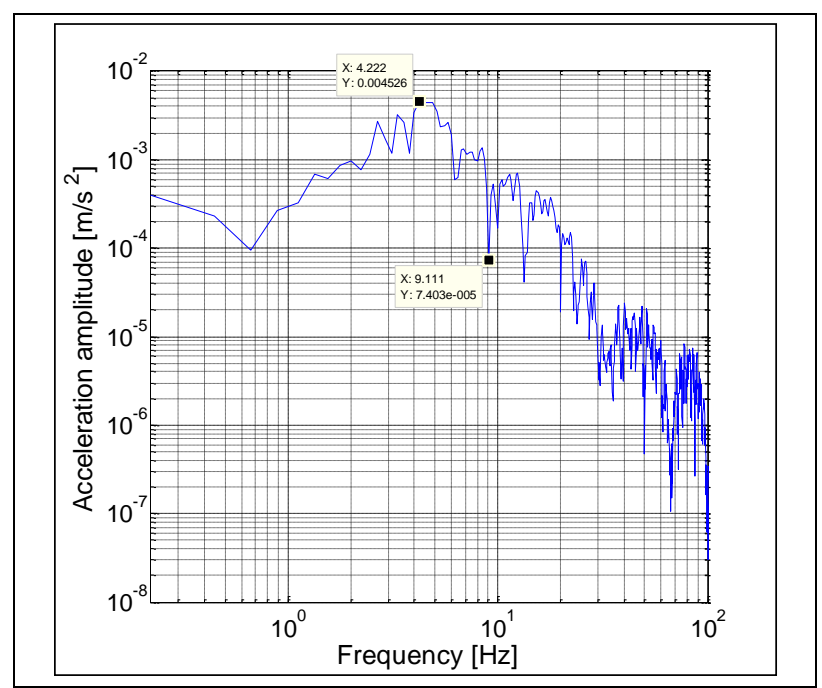

Fig. 14. Spectral composition of acceleration in nonlinear case

\subsection{Phases domain analysis}

Graphical representation of displacement - velocity dependence constitutes a valuable indication about system stability evolution. From the diagrams depicted in Fig. 15 and Fig. 16 results that system evolution has a stable character for both cases (linear and nonlinear).

The differences only have the qualitative character showing the strong dynamics of nonlinear case versus the linear.

\subsection{Power spectral density}

The diagrams showing the power spectral density for the two proposed cases of linear, respectively nonlinear system evolution (see Fig. 17 and Fig. 18) reveal that for the nonlinear case a very considerable quantity of the average power of the signal is worn by the spectral components with frequency in $(0 \ldots 8) \mathrm{Hz}$ range whereas that for the linear case this values interval is much diminished at $(0 . .4) \mathrm{Hz}$.

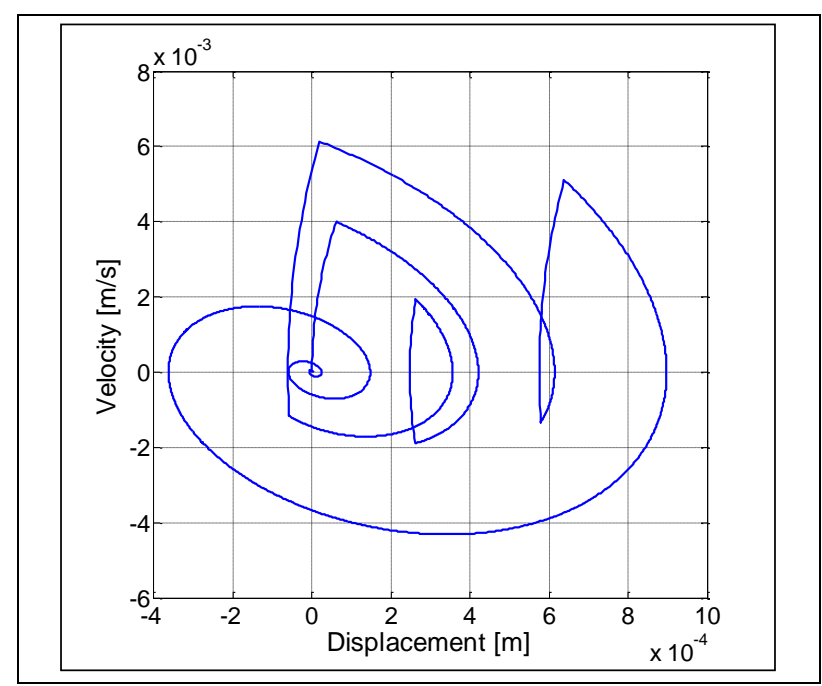

Fig. 15. Phase domain diagram: linear case

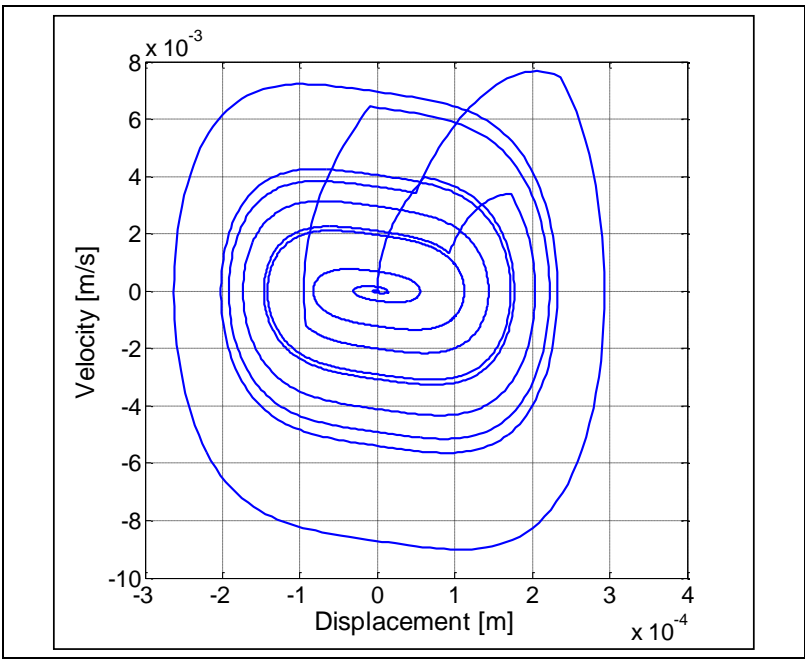

Fig. 16. Phase domain diagram: nonlinear case 


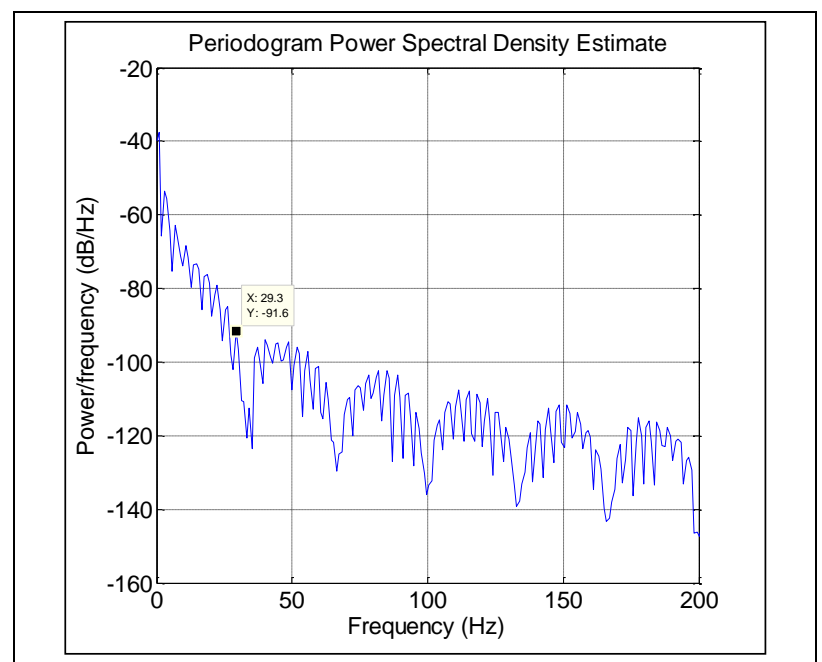

Fig. 17 .Power spectral density for linear case

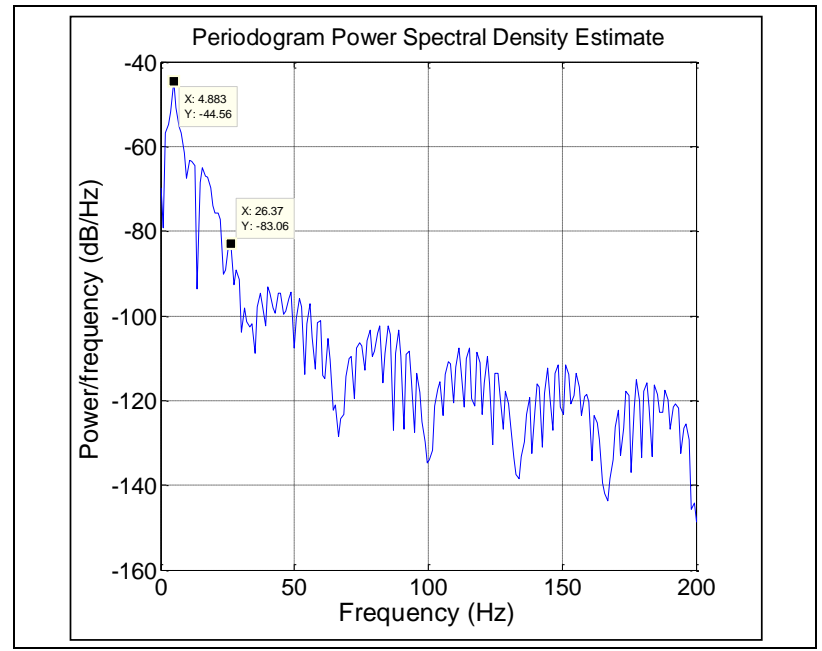

Fig. 18. Power spectral density for nonlinear case

\section{CONCLUSION}

This study demonstrates the influences of the nonlinear behaviour of the rubber-based bearings about the deck bridge dynamic response in case of road traffic impulsive excitations. Based on the theoretical model proposed and presented in this paper it can be elaborated a regular method intended for the predictive maintenance of the ordinary working state of the rubber-based bearings. This method can contain the next steps as follows

- At managing to action of the viaduct, when dynamic insulation systems are new and, accordingly, it can be supposed having a linear behaviour characteristic, it will be done instrumental tests based on which it will be evaluated a set of reference parameters of the bridge dynamics.

- After a certain time period of ordinary utilization of viaduct the experimental tests will be repeated for the same conditions and hypothesis like the managing to action time; through this analysis it have to be following the quantitative and qualitative characterization of the modification in evolution of the reference parameters.

- Based on the two sets of values for the reference parameters it can be evaluate a comparative analysis with the final purpose to dignify the differences between these; hereby the possible differences which will be identified and quantified put into the evidence the damages of the visco-elastic insulation devices and the emergency of the failure state of these.

These correlations between the nonlinear behaviour of the elastic component of rubber-based bearings and the modifications which appears into the structure dynamic response was only theoretical dignified, but this study opens the opportunity of the instrumental testing "in situ" of this analytical approach.

\section{ACKNOWLEDGMENTS}

This work was supported by UEFISCDI (CNCSISUEFISCSU), project number PN II-RU-PD code $597 / 2010$

\section{REFERENCES}

[1] Leopa, A., (2011). The Impulsive Loading Influence on Dynamic Response Parameters of the Viaduct Type Structure, The annals of "Dunarea de Jos" University of Galati, Fascicle XIV Mechanichal Engineering, No. 2, 2011, ISSN 1224-5615, p. 65 - 67

[2] Amaddeoa, C., Benzonib G., D'Amorea, E., (2008), Damage Detection Algorithm for Bridge With Anti-Seismic Devices. International Workshop Civil Structural Health Monitoring 2" WIM, Load Capacity, and Bridge Performance in the Context of Risk Assessment, Maintenance and Life Cost Based Design, 2008 - Taormina - Sicily (Italy)

[3] Final report on testing for Transylvania highway viaduct, ICECON SA, Bucharest, 2009

[4] Leopa, A., Nastac, S., Dragan, N., Debeleac, C., (2011), Considerations on the Influence of Viscoelastic Behavior of Nonlinear Systems Bearing on the Dynamic Constructions Response, International Conference on Structural Engineering Dynamics, Tavira, Portugalia, 2011, ISBN 978-989-96276-1-1

[5] Dragan, N., (2010), Instrumental Analysis of the Reinforced Concrete Bridges Subjected to Dynamic Forces From the Traffic, The annals of "Dunarea de Jos" University of Galati, Fascicle XIV Mechanichal Engineering, No. 2, 2010, ISSN 1224-5615, p. $35-40$

[6] Bratu, P., (2008). Theoretical Mechanics, Impuls House Publishing, Romania

[7] Dragan, N., (2010), Modal Calculus of the Reinforced Concrete Bridges Modeled as a Rigid Solid Beared on Viscous Elastic Neoprene Supports, The annals of "Dunarea de Jos" University of Galati, Fascicle XIV Mechanichal Engineering, No. 2, 2010, ISSN 1224-5615, p. $27-34$

[8] Ghinea, M., Fireteanu, V., (2003), Matlab - Calcul numeric, grafica, aplicatii, Teora House Publishing, Romania

[9] Leopa, A., Nastac S., (2008), Dynamic Behaviour of Foundations in Linear and Nonlinear Elastic Characteristics Hypothesis, WSEAS Transactions on Applied and Theoretical Mechanics, Issue 4, Vol.3, April 2008, ISSN 1991-8747, pp. 145-154 